\title{
POLICY DESIGN IN FLOOD RISK MANAGEMENT: STUDYING POLICY PREFERENCES IN THREE SUB-CATCHMENT AREAS IN SWITZERLAND
}

\author{
ANIK GLAUS \\ Institute of Political Science and Oeschger Centre for Climate Change Research, \\ University of Bern, Switzerland
}

\begin{abstract}
Floods are an extensive environmental problem that touches upon several policy sectors, decisionmaking levels, and territories simultaneously. To effectively cope with floods, decision-makers increasingly need to consider cross-sectoral, multi-level, and transterritorial solutions. However, such boundary-spanning policy solutions converge with traditional sector-, level-, and territory-oriented flood risk management. Overcoming these particular interests and moving towards a more integrated approach is therefore a complex task. However, combining policies from different entities into an integrated approach, actors' policy preferences for single instruments or instrument mixes are key. With the aim of understanding effective policy design in flood risk management, this paper studies whether actors' preferences for flood risk management instruments align. We take the ideal case of Swiss flood risk management and analyze three hydrological sub-catchments of the Aare, Kander and Thur rivers. We surveyed and interviewed public and private actors involved in flood risk management belonging to multiple sectors, levels, and territories on their preferred instruments and instrument mixes. Based on these preference data, we evaluated the effectiveness of flood risk management measures and measure mixes via an index. Results suggest that actors' focus on traditional sector-, level-, and territory-oriented flood risk management policies outweighs preferences for more integrated approaches in Switzerland.

Keywords: policy design, instrument mix, policy preferences, flood risk management.
\end{abstract}

\section{INTRODUCTION}

Flooding offers an ideal example for studying policy design concerning complex environmental problems in complex multi-dimensional policy settings. Increasing frequencies and magnitudes of floods and growing flood damages in Europe pose a high risk for population and infrastructure. The cross-sectoral, multi-level, and transterritorial nature of flooding calls for effective policy design that can exploit synergies between different sectors, levels, and territories. Traditional flood risk management is, however, often organized in sectoral, political, and territorial "silos". Overcoming these particular interests and moving towards coordinated and boundary-spanning policies, known as integrated flood risk management, is a complex task and often lacks political support. Complex environmental problems such as floods that are characterized by a mismatch between affected sectors, levels, and territories require policy solutions capable of connecting these disentangled parts [1]. Some concepts in the literature, such as collaborative or polycentric governance [2], or functional spaces [3], suggest approaching complex environmental problems with an effective instrument mix that addresses public and private actors belonging to multiple sectors, levels, and territories simultaneously. Policy designs including an effective instrument mix rather than single policy instruments can fulfil various goals, interests, and priorities, address numerous challenges, and reach multiple actors. In designing an effective instrument mix, it is crucial to understand the context in which an instrument mix applies, i.e. the plurality of actors' norms, values, and interests, which can lead to a variety of often divergent preferences for different solutions [4]. Thus, previously existing arrangements, 
actor constellations, and long-standing preferences in a particular setting, influence actors' instrument choice [5]. Research on policy preferences for effective instrument mixes, however, is still limited. Consequentially, this study poses the following research question: How do multiple actors' preferences for an effective instrument mix vary between sectors, levels, and territories?

Addressing this research question helps to provide insight into and evaluate multiple actors' divergent preferences for different policies. An instrument mix only has the potential to effectively manage cross-sectoral, multi-level, and transterritorial complex environmental problems when supported and preferred by actors belonging to the affected sectors, levels, and territories. Following the literature, it is difficult to arrive at a common perspective between a multitude of actors with significantly different interests [1]. In this vein, the study is based on the assumption that integrated flood risk management is only possible if multiple actors belonging to different sectors, levels, and territories participate in policy design as their preferences are driven by their specific "silo".

Empirically, the study analyzes flood risk management in three hydrological subcatchment areas of the Aare, Kander, and Thur rivers in Switzerland. Public and private actors belonging to different sectors and levels are surveyed on their preferred instrument mix in flood risk management. Based on this data, the effectiveness of instrument mixes, operationalized by the number (density), coerciveness (intensity) [6], and inclusiveness (balance) of instruments, in Swiss flood risk management are evaluated. By connecting the two well-known criteria density and intensity, and adding a third new indicator balance, an "Effective Policy Mix Index" is constructed to compare preferred instrument mixes between multiple actors. In combination with the index, qualitative in-depth interviews with key actors involved in flood risk management were conducted to contextualize preferences for particular instrument portfolios.

\section{THEORETICAL FRAMEWORK}

\subsection{Policy design: instruments, mixes, and preferences}

Policy design, and particularly instrument selection, is an inherent part of the policy formulation process [5]. Designing a policy implies that goals and targets are defined and connected to instruments expected to achieve the defined goals. As such, a policy attempts to alter aspects of social behavior and alleviate an underlying societal problem [7]. In particular, the instrumental orientation of modern policy design studies is central. For instance, a broad literature on instruments emerged, which can be delineated between an "old" school of traditional instrument studies and a "new" school of policy design orientation [8].

The "old" school of instrument studies analyzed different kinds of instruments, their characterization, and into which instrument types these instruments could be categorized (e.g. based on state action and government resources [9], degree of state intervention [10], or policy targets and their behavior [11]). Of note is that the "old" school of instrument studies was often criticized for its focus on single instruments. Governments often adopt multiple instruments in a policy field and bundle them in policy programs or instrument portfolios [12]. Therefore, the "new" school of policy design orientation began to assess more complex policy mixes including multiple instruments and identify complementarities and conflicts within instrument mixes [13]. Often new mixes are constrained by the instrument choices that have become institutionalized previously in a policy field. Policy makers choose and combine some specific instruments rather arbitrarily, especially those already well known 
from other contexts. In addition, governments seldom abolish existing instruments, and instead often introduce new instruments on top of existing ones.

The "new" policy design studies' approach provides valuable insights into the design of more complex forms of policies in challenging contexts, such as complex environmental problems. At the same time, however, in designing and selecting a well-functioning, productive instrument mix in a complex policy design process, it is of major importance to understand policy makers' preferences for particular instruments in a specific context [14]. Thus, previously existing arrangements, long-standing preferences, or the political context within which policy makers operate can shape the design of an instrument mix [5].

\subsection{Evaluating design features of policy portfolios}

To select from a wide range of instruments for a mix, instruments are often compared in terms of their effectiveness. Evaluating the effectiveness of instrument mixes or policy portfolios across time, policy fields or regions, many policy design studies use the two dimensions density and intensity [6]. Density explores the number of policies or instruments that are applied within a policy field over time [15]. Meanwhile, to account for the content of instruments [16], intensity provides information about the level of regulatory standards (e.g. emission limits) and their scope of application (e.g. specific branches).

This study aims to construct an index ("Effective Policy Mix Index"), which also builds on Knill et al. [6], [15] density and intensity dimensions, while adding a third dimension of instrument balance (see [17]). Balance facilitates the assessment of actors' preferences for a balanced instrument mix, including tools of all instrument types available in a particular policy field. Thus, the index does not exclusively evaluate the number and coerciveness of instruments, but additionally indicates the inclusiveness or the extent to which actors are willing to support a mix's instrument type balance, i.e. instruments representing multiple actors' preferences. Consequentially, the probability of eventually adopting and implementing an effective instrument mix in a complex context increases [17].

\subsection{Actor-centered hypotheses}

According to Landry and Varone [18], three groups of participants should be considered in a policy design process. First, policy makers (e.g. elected representatives), with re-election as their ultimate goal, are interested in formulating flexible policy designs, because they must react to citizens' changing preferences (i.e. policy responsiveness). Second, policy implementers (e.g. administrative agencies) prefer policy designs that maximize their financial resources and decision-making powers. Finally, target groups seek to influence policy designs in order to minimize their costs and maximize their benefits that come along with the introduced instruments. Because actors have traditionally not been equally affected by policy design processes, this differentiation of participants in three groups is key [19]. Some actors ("sources") are identified as causing a particular problem (e.g. water pollution), while other actors ("victims") are negatively affected by the current problem [20]. "Victim" actors wish to be compensated and see the problem (re)solved with the most effective solution, i.e. tend to prefer an instrument mix consisting of multiple, coercive, and inclusive instruments that targets a problem successfully. The "source" actors, however, whose stance is threatened by the introduced policies, wish to keep their costs low and their flexibility high [18], while attempting to deflect responsibility for the problem, i.e. prefer an instrument mix consisting of few, less coercive and less inclusive instruments influencing them only 
minimally or not at all. Consequently, depending on actors' affectedness and role in a policy design process, their demands concerning an effective instrument mix differ.

Actors in a policy design process tend to agree on similar policy designs when they share similar core beliefs regarding a specific issue (according to the Advocacy Coalition Framework (ACF) [4]). For instance, similar beliefs can be expressed in shared fundamental norms and values, but also in preferences for the same instruments in approaching a specific problem [19]. On the fundament of similar core beliefs, actors form coalitions in a policy process. In particular, actors facing an overlapping problem tend to work collaboratively in addressing their mutual hindrance and hence share similar beliefs in its resolution. Such shared beliefs are often the case for actors belonging to the same policy sector (or policy subsystem in $A C F$-language) addressing a particular issue from a similar perspective. Since complex environmental problems often create "victims", i.e. directly affected sectors, actors tend to agree on similar coordinated and effective policy designs. Actors belonging to sectors, which are less directly affected by a problem, however, tend to favor non-coordinated single instruments.

H1a: Actors belonging to a policy sector being directly affected by a problem tend to prefer an effective instrument mix.

H1b: Actors belonging to a policy sector being indirectly affected by a problem tend to reject an effective instrument mix.

As is the case with actors belonging to the same sector, actors belonging to the same decision-making level tend to agree on similar policy designs in a policy process [21]. In decentralized political systems, such as Switzerland, the national, sub-national, and local government levels often share policy competences and tasks in order to effectively address various complex problems. Despite adopting a multi-level lens, such shared policies treat different aspects of a problem at each of the levels individually. Separate problem handling leads to the development of a common sense of problem understanding, fosters collective action, and supports learning processes at each level [22]. This level-specific understanding of a current problem contributes to shared beliefs and agreements on similar policy designs [21]. Since complex environmental problems mostly manifest on the local level, local actors tend to agree on similar coordinated and effective policy designs. National and sub-national actors, however, positioned further away from a problem's consequences, are only indirectly affected by the problem, and therefore tend to favor non-coordinated single instruments.

H2a: Actors belonging to a decision-making level being directly affected by a problem tend to prefer an effective instrument mix.

H2b: Actors belonging to a decision-making level being indirectly affected by a problem tend to reject an effective instrument mix.

\section{CASE STUDY}

With its geographic position at the source of several major European rivers, many smallsized and densely populated areas, and increasing climate change impacts, some Swiss regions are heavily exposed to flood risks. This historical record explains Switzerland's long experience with flood risk management and a wide range of different flood-related policies and instruments. Swiss flood risk management has traditionally been characterized by an infrastructure-oriented regime, slowly shifting towards a more nature-oriented and sustainable spatial planning approach, including new integrative and coordinated risk management elements. To this day, technical instruments remain the most widespread 
instrument type [23]. In complex settings, however, where flooding potentially affects actors belonging to multiple sectors, levels, and territories, the demand for more integrative, coordinated, and boundary-spanning instrument types increases: technical instruments are completed by spatial planning, ecological river restoration, and information [24].

The study analyzes actors' preferences in the case of flood risk management in three hydrological sub-catchment areas in the river basins of the Aare, Kander, and Thur in Switzerland. A postal mixed-mode survey based on standardized questions is designed to gather data on actors' instrument preferences in the three sub-catchment areas. Additionally, 21 key actors are interviewed in semi-structured interviews. To identify the central actors of the three flood risk management processes, the commonly used (in the social sciences) decisional, positional, and reputational approaches are applied. The actor sample includes representatives from the federal, cantonal, and municipal administration, regional associations, interest groups, such as nature conservation organizations and leisure clubs, and economic, infrastructure, and scientific actors. 206 actors are surveyed in total ( 82 in the Aare, 63 in the Kander, and 61 in the Thur sub-catchment) of which 142 or $69 \%$ responded.

\section{METHOD}

\subsection{Operationalization of "Effective Policy Mix Index"}

To construct an index capturing actors' preferences for an effective policy mix, three dimensions of an instrument mix are measured: density, i.e. the number of instruments, intensity, i.e. the coerciveness of instruments, and balance, i.e. the inclusiveness of instruments. Density, intensity, and balance operationalizations are based on a survey question measuring actors' preferences for different flood risk management instruments. For each item in a statement battery, two single instruments belonging to different instrument types (technical, spatial planning, ecological, informative) are contrasted. The actors express their preferences for one or the other instrument on a two-dimensional four-point Likert scale ranging from full or partial agreement for one instrument to full or partial agreement for the other instrument. In so doing, actors assign to each of the two flood risk management instruments a level of preference between 1 (weak) and 4 (strong).

This preferences data provides the basis for the construction of the index indicators density, intensity, and balance. The three indicators are combined in a multiplicative index. Thus, the higher the number, coerciveness, and inclusiveness of their preferred instruments, the higher actors' preferences for an effective policy mix.

As is true for many empirical studies preceding this one, the indicator density is measured by counting the number of preferred instruments. An instrument is counted when actors assign at least a preference level of 3 or 4 (partial or full agreement). The number of preferred instruments is summarized for each actor and lies between 0 and 12 (Kander and Thur subcatchments), and 0 and 10 (Aare sub-catchment), respectively. Finally, the values of the indicator density are normalized to a range from 0 to 1 .

The indicator intensity can be measured empirically in various ways. In this study, the level of state action and resources available to public authorities, i.e. the coerciveness of the preferred instruments, is crucial. Hood's categorization distinguishes between nodality, organization, treasure, and authority, with increasing coerciveness from the first to the last [9]. Henstra [25] adjusts this categorization to climate adaptation instruments, which sets the foundation for the coerciveness evaluation of actors' preferred flood risk management instruments in this study. First, each instrument is assigned to a coerciveness category from nodality to authority (where treasure, for reasons of effectiveness, is divided into ecosystem 
management and public goods and services). Subsequently, for every actor, the mean value of preferences per coerciveness category is calculated. Next, these average preferences values are weighted from 1 to 5 , where the least coercive category (= nodality) receives a value of 1 and the most coercive category (= authority) a value of 5 . This weighting process corresponds to the assumption that directly affected actors prefer instruments that are more coercive. Finally, the values of the indicator intensity are normalized to a range from 0 to 1 .

The indicator balance uses the multiple combinations of instrument types resulting from the survey question. First, every combination of the four instrument types - technical, spatial planning, ecological and informative instruments - is represented at least twice in the survey question (with different contrasted single instruments, however). Actors' preferences for the same instrument type over the other in both combinations are evaluated, to see whether they hold consistent preferences. Second, the number of instrument types in which actors have consistent preferences in both combinations is summarized. The higher the number of instrument types where actors show consistent preferences, the more they prefer a balanced mix of different instrument types. Holding preferences for all four instrument types is the maximum value and corresponds to actors' preferences for a fully balanced mix of instrument types. Finally, the values of the indicator balance are normalized to a range from 0 to 1 .

\subsection{Actors}

For the policy sector, actors in Swiss flood risk management can be distinguished in seven different sectoral groups, three of which are water-related sectors - water use, protection of water, flood protection - and four of which are external sectors - cities and municipalities, agriculture and forestry, economy and infrastructure, science. Distinguishing between the water-related sectors is of utmost importance, because often the goals of using water (e.g. drinking water), protecting water (e.g. wastewater treatment), and flood protection (e.g. infrastructure construction) conflict with each other. For actor level, actors are distinguished according to whether they belong to the national, cantonal, regional, or local decision-making level. Actors from the three sub-catchment areas are combined into one larger sample; however, their respective sub-catchments serve as control variables.

\subsection{Method of data analysis}

First, actors' index results are analyzed univariately and compared between sectors, levels, and sub-catchments. In the bivariate analysis, Spearman's rank order correlation and Cronbach's alpha are computed for the three index indicators. Second, index results are complemented by insights gained through several in-depth interviews with key actors. These interviews provide the study with the necessary case knowledge, which helps to evaluate and interpret the index's and the three indicators' results. As such, this study adopts a mixedmode method, combining quantitative and qualitative preferences data.

\section{RESULTS}

\subsection{Descriptive analysis of "Effective Policy Mix Index"}

The mean value for the index is 0.17 , which is low and indicates that the surveyed actors generally prefer non-coordinated single instruments to manage flood risks. However, examining the indicators density, intensity and balance individually relativizes the impression that actors reject all aspects of an effective instrument mix. Instead, actors seem to prefer a mix including a medium number of instruments (around 5-6 instruments), with 
mid-coercion (some technical and/or spatial planning instruments combined with some ecological and/or informative instruments), and belonging to a balanced number of instrument types (around 2-3 instrument types).

Spearman's rank order correlation analysis of the three indicators reveals that density, intensity, and balance are significantly and positively correlated to each other (densityintensity: 0.64/density-balance: 0.36/intensity-balance: 0.40). The Cronbach's alpha measuring the reliability of the index and the importance of each indicator for the index is consistent with the Spearman's rank order correlation: 0.77 (CI: $0.70,0.83$ ), i.e. moderate to high, signifying that the indicators density, intensity, and balance are linked and can be combined in an index.

\section{2 "Effective Policy Mix Index" by sector and level}

Fig. 1 illustrates actors' preferences by sector and level. First, it is of note that the less directly affected sectors water use (cantonal and regional $=0.20$ ) and water protection (national $=$ $0.19 /$ cantonal $=0.20$ /regional $=0.16$ ) carry on average higher preferences for the index than the directly affected flood protection sector (national $=0.07 /$ cantonal $=0.24 /$ regional and local $=0.15$ ). While actors in the water use and water protection sectors show homogeneous preferences for the different levels, in the flood protection sector, no homogeneous preferences can be found: national actors have low preferences for a mix, while cantonal actors in comparison show higher preferences. Regional and local actors have medium preferences. Second, the same situation can be observed for the agriculture and forestry sector (national $=0.12 /$ cantonal $=0.18$ /regional $=0.10$ ), a water-external sector strongly affected by flood risk management instruments to be implemented. Cantonal actors have slightly higher preferences for a mix than actors on the national or regional level.

Fig. 2 illustrates actors' preferences by sectors and sub-catchments. Results are consistent: actors from the flood protection and the agriculture and forestry sectors show heterogeneous preferences for a mix in comparison with the other sectors displaying more homogeneous preferences. For the flood protection sector, actors in the Aare sub-catchment (0.24) show higher preferences than actors in the Kander and Thur sub-catchments (both 0.14). Similarly, for the agriculture and forestry sector, actors in the Thur sub-catchment $(0.22)$ express higher preferences for a mix than do actors from the Aare and Kander sub-catchments (both 0.07).

\subsection{Interviews}

Several actors emphasize in the interviews that effective flood risk management requires a combination of multiple equivalent instruments. However, an optimal instrument mix depends on the location and the technical options, and may change frequently. Regarding the instrument types, almost half of the actors state that spatial planning or ecological instruments should be given priority, but that the traditional technical instruments are implemented more quickly and in a more practical way. These statements allow for embedding the index's descriptive results: the overall index results are low, i.e. in general, actors prefer noncoordinated single instruments. Nonetheless, the balance of different instrument types appears an important dimension in the mix. Technical instruments remain the most important instrument type, but actors state that they prefer to combine them with spatial planning and/or ecological instruments. Thus, actors wish to combine at least 2-3 instrument types rather than rely only on technical instruments. 


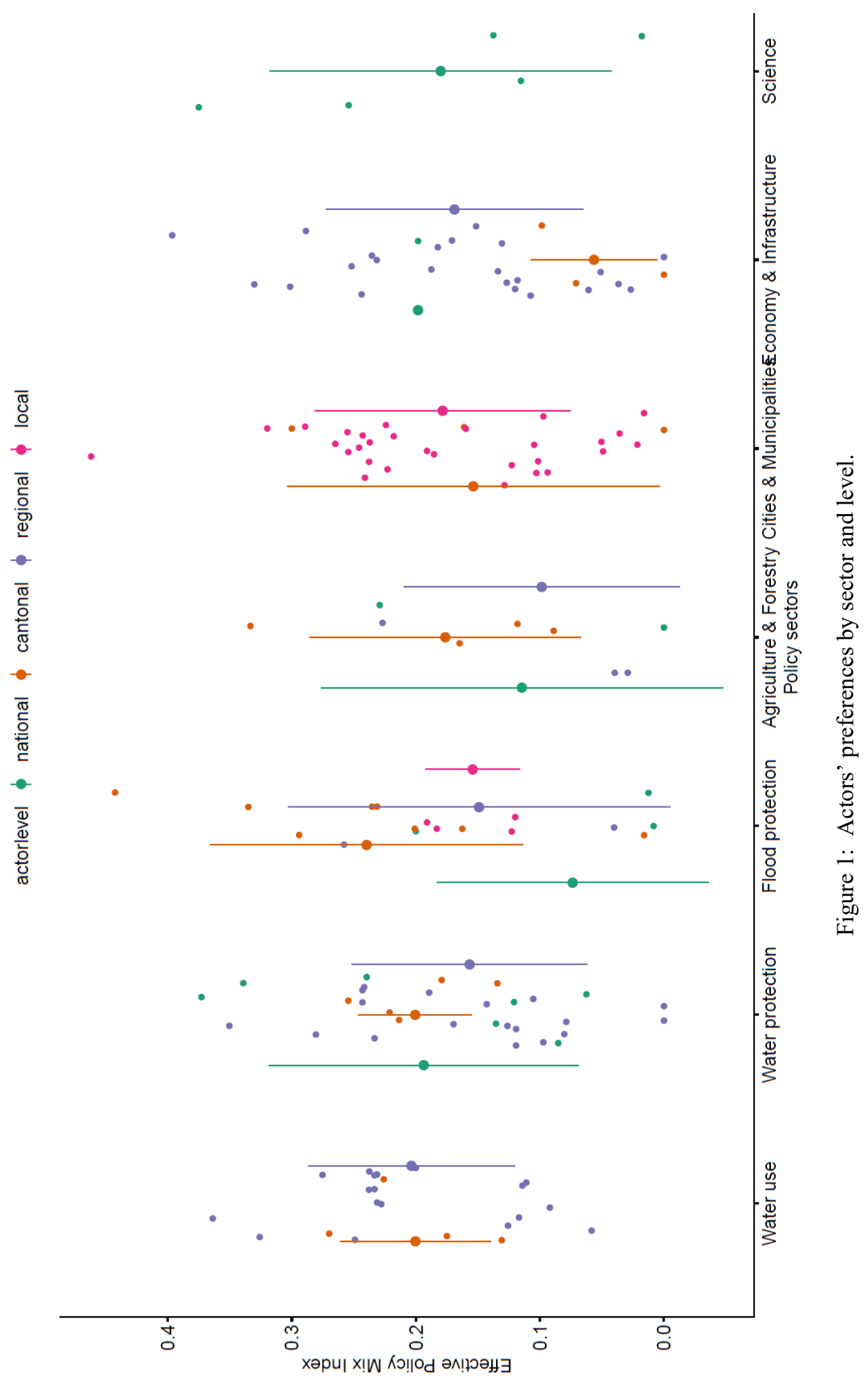




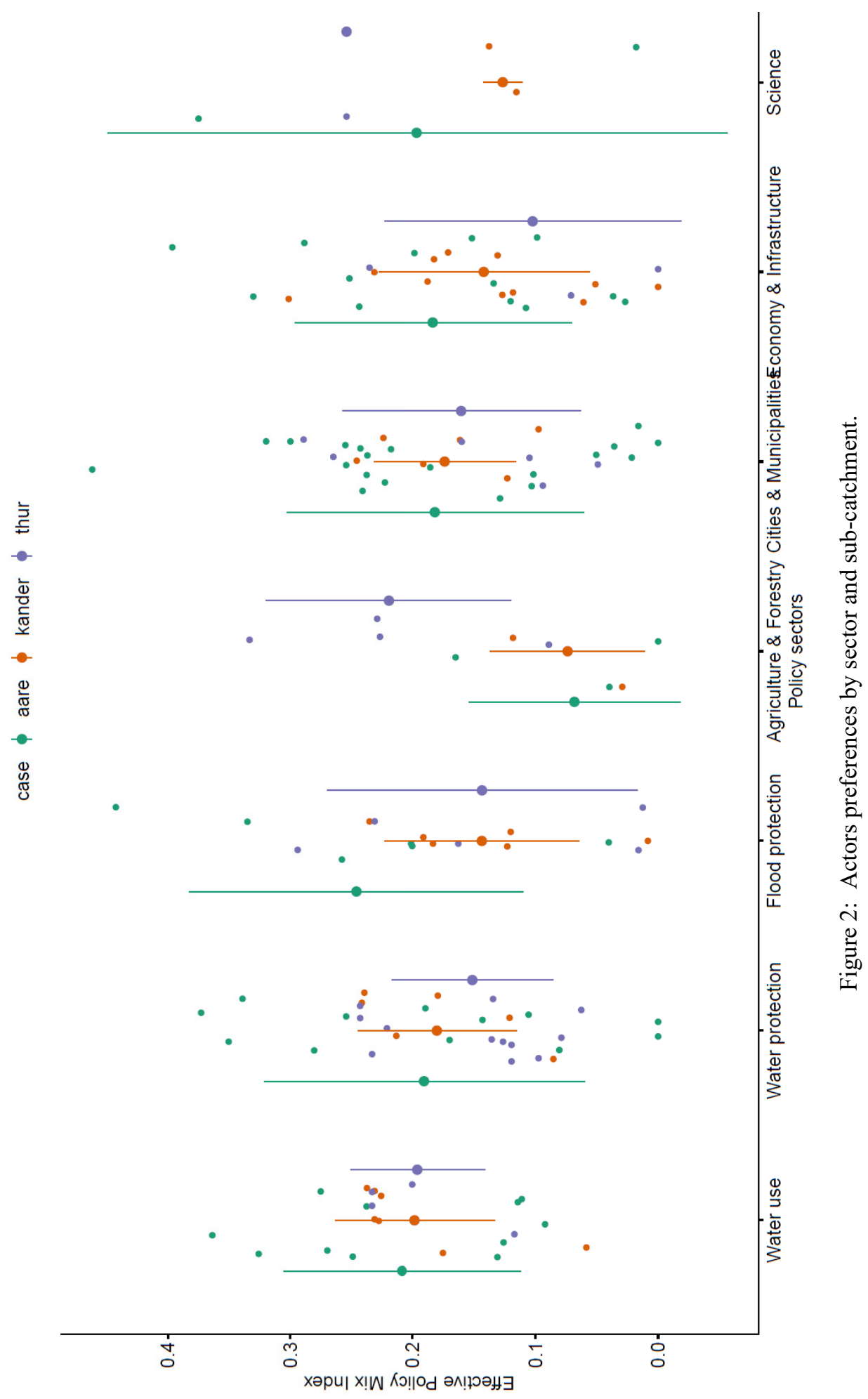


As for actors' preferences by sector, level, and sub-catchment, the interviews shed light on two points. First, actors' heterogeneous preferences in the Flood protection sector are notable, mainly the high cantonal preferences compared with the low national together with medium regional and local preferences in the Aare sub-catchment. Several actors emphasize the canton's key role (project leader) for the flood risk management project and its strong support of a participative policy-making process. The coordinated and regulated communication between canton, municipalities, and other actors helped to weigh different interests against each other and to find a feasible solution for all affected actors. It is in the canton's interest to provide coordinated flood risk management involving as many actors as possible in the policy design process. Accordingly, the cantonal Flood protection actors in the Aare sub-catchment show higher preferences for an effective instrument mix than do actors from the other sectors, levels, and sub-catchments. Second, cantonal actors' higher preferences in the agriculture and forestry sector, mainly in the Thur sub-catchment, can be explained by the controversial discussion on land use to implement flood risk management instruments. While several actors in the interviews support the use of agricultural or forested land to implement instruments by simultaneously compensating the landowners for their losses, some actors oppose this process. In the flood risk management project in the Thur sub-catchment, the canton held a key role in the form of project leader, who efficiently negotiated with forest landowners to purchase a significant parcel of land to implement flood risk management instruments by compensating landowners for their losses. This approach helped the cantonal actors to find a comprehensive policy solution including landowners' and other actors' interests. Therefore, similar to the cantonal flood protection actors in the Aare sub-catchment, the cantonal agriculture and forestry actors in the Thur sub-catchment have higher preferences for an effective policy mix than do actors from the other sectors, levels, and sub-catchments. These two examples illustrate how actors can diverge in their preferences for an effective instrument mix, depending not only on their affectedness by a problem, but also by their role in the policy design process, i.e. their responsibility to make adequate decisions in the form of instruments.

\section{DISCUSSION}

Our results reveal that, on average, most actors express similar preferences regarding an effective instrument mix, both within and across multiple sectors and levels. However, there are two sectors - flood protection and agriculture and forestry - in which actors show more heterogeneous preferences across levels, i.e. have higher or lower preferences compared to actors' average preferences in the other sectors. These findings by sectors and levels demonstrate the following: (1) Actors' preferences within the same sector can differ substantially, regardless of whether a sector is directly or indirectly affected by flood risks. Actors' preferences are neither consistently high in the directly affected flood protection sector, nor consistently low in the other indirectly affected sectors. Therefore, hypotheses 1a and $1 \mathrm{~b}$ can neither be fully confirmed nor fully rejected. (2) The same observation is true for actors' preferences by levels. One cannot assume that actors belonging to the national and cantonal levels are only indirectly affected by flood risks, and thus generally prefer less effective mixes, while the local and regional levels are always directly affected by flood risks, and thus prefer more effective mixes. In the examples presented above, the cantonal level is often directly affected by flood risks, such that the canton plays a key role in solving problems and negotiating with other affected actors, therefore indicating overall higher preferences for an effective mix. On the other hand, regional and local actors demonstrate both comparably high and low preferences for an effective mix. Therefore, hypotheses $2 \mathrm{a}$ and $2 \mathrm{~b}$ can neither be fully confirmed nor fully rejected. 
In conclusion, actors belonging to a directly or indirectly flood-affected sector or level do not necessarily share preferences for an effective instrument mix. Their preferences depend on many more factors than exclusively belonging to the same defined entity. Each of the surveyed sub-catchments has its own specific actor constellations and conflicts between certain actor groups (e.g. flood protectors versus farmers). Another factor with the capacity to influence actors' preferences is their role in the policy design process. According to the literature [26], sub-national actors can strengthen the connection between national and local levels and guarantee an efficient flow of information within the three levels. This gatekeeper role can help to build a common understanding of a current problem, and thus enhance efficient task execution and enable effective policy-making. In line with Ostrom's polycentric governance approach, medium-scale governance units in the study's context are enforced with policy-making and implementation responsibilities [2].

\section{CONCLUSION}

Complex environmental problems, such as increasing flood risks, touch upon various sectors, levels, and territories simultaneously. This complexity challenges policy makers to find adequate policy solutions. Some concepts offered in the literature provide ideas on how to approach complex environmental problems with more effective policy designs supported by multiple actors with various goals, interests, and priorities. In order to discern the likelihood of designing and implementing such encompassing solutions, this study analyzes actors' preferences for effective instrument mixes in three Swiss sub-catchment areas in the case of flood risk management. Results illustrate that actors' preferences for an effective policy mix are low, and vary substantially between sectors, levels, and sub-catchments. Cantonal actors in some specific sectors show slightly higher preferences for an effective mix than the other actors do, which can mainly be attributed to case specificities and their key role in policy design processes. Taking into account such case-specific policy contexts and long-standing arrangements seems to be of major importance in evaluating actors' preferences for an effective mix. The study's findings also show that, in general, actors' preferences continue to promote sectoral and level-oriented single instruments rather than a coordinated and effective policy mix. Actors are not (yet) willing to support effective policy solutions and move towards integrated flood risk management in Switzerland.

This study's findings could have practical implications for future research on the design of effective policy mixes to address complex problems. In fact, actors' preferences to implement instruments in an effective mix are comparatively low for the case of Swiss flood risk management. Nevertheless, an analysis of the index's single indicators shows that there is potential for solving complex problems via effective instrument mixes. Adding a third indicator balance to the well-known combination of the indicators density and intensity proves a difficult endeavor, but as the study's results indicate, actors in Swiss flood risk management often support balanced instrument types in an instrument mix. The indicator balance reflects the extent to which actors are willing to compromise with other actors and accept other goals, interests, and priorities in an effective instrument mix. In a number of indepth interviews, actors confirm this tendency by stating that several instrument types in flood risk management must be combined in order to achieve a feasible instrument mix, rather than to solely rely on the traditional technical instruments. It is evident, however, that there exists neither a one-size-fits-all design nor an ideal model to promote effective policy solutions [7]. 


\section{REFERENCES}

[1] Ingold, K., Driessen, P.P.J., Runhaar, H.A.C. \& Widmer, A., On the necessity of connectivity: Linking key characteristics of environmental problems with governance modes. Journal of Environmental Planning and Management, 62, pp. 1821-1844, 2019. DOI: 10.1080/09640568.2018.1486700.

[2] Ostrom, E., Polycentric systems for coping with collective action and global environmental change. Global Environmental Change, 20, pp. 550-557, 2010. DOI: 10.1016/j.gloenvcha.2010.07.004.

[3] Varone, F., Nahrath, S., Aubin, D. \& Gerber, J., Functional regulatory spaces. Policy Sciences, 46, pp. 311-333, 2013. DOI: 10.1007/s11077-013-9174-1.

[4] Jenkins-Smith, H., Nohrstedt, D., Weible, C. \& Sabatier, P., The advocacy coalition framework: Foundations, evolution, and ongoing research. Theories of the Policy Process, 3rd ed., eds P.A. Sabatier \& C.M. Weible, Westview Press: New York, pp. 183-223, 2014.

[5] Bressers, H. \& O'Toole, L.J., Instrument selection and implementation in a networked context. Designing Government: From Instruments to Governance, eds P. Eliadis, M. Hill \& M. Howlett, McGill-Queen's University Press: Montreal, pp. 132-153, 2005.

[6] Knill, C., Schulze, K. \& Tosun, J., Regulatory policy outputs and impacts: Exploring a complex relationship. Regulation and Governance, 6, pp. 427-444, 2012.

DOI: 10.1111/j.1748-5991.2012.01150.x.

[7] Howlett, M., Beyond Good and evil in policy implementation: Instrument mixes, implementation styles, and second generation theories of policy instrument choice. Policy and Society, 23, pp. 1-17, 2004. DOI: 10.1016/S1449-4035(04)70030-2.

[8] Howlett, M., Mukherjee, I. \& Woo, J.J., From tools to toolkits in policy design studies: The new design orientation towards policy formulation research. Policy and Politics, 43, pp. 291-311, 2015. DOI: 10.1332/147084414X13992869118596.

[9] Hood, C., The Tools of Government, Chatham House Publishers: Chatham, NJ, 1986.

[10] Vedung, E., Policy instruments: Typologies and theories. Carrots, Sticks and Sermons: Policy Instruments and Their Evaluation, eds M.L. Bemelmans-Videc, R.C. Rist \& E. Vedung, Transaction Publishers: New Brunswick, NJ, pp. 21-58, 1998.

[11] Schneider, A. \& Ingram, H., Behavioral assumptions of policy tools. The Journal of Politics, 52, pp. 510-529, 1990.

[12] Salamon, L.M., The Tools of Government: A Guide to the New Governance, Oxford University Press: Oxford, 2002.

[13] Howlett, M., From the "old" to the "new" policy design: Design thinking beyond markets and collaborative governance. Policy Sciences, 47, pp. 187-207, 2014. DOI: 10.1007/s11077-014-9199-0.

[14] Bressers, H. \& O’Toole, L.J., The selection of policy instruments: A network-based perspective. Journal of Public Policy, 18, pp. 213-239, 1998.

[15] Knill, C., Schulze, K. \& Tosun, J., Politikwandel und seine messung in der vergleichenden staatstätigkeitsforschung: Konzeptionelle probleme und mögliche alternativen. Politische Vierteljahresschrift, 51, pp. 409-432, 2010. DOI: 10.1007/s11615-010-0022-z.

[16] Schaffrin, A., Sewerin, S. \& Seubert, S., Toward a comparative measure of climate policy output. Policy Studies Journal, 43, pp. 257-282, 2015. DOI: 10.1111/psj.12095.

[17] Schmidt, T.S. \& Sewerin, S., Measuring the temporal dynamics of policy mixes: An empirical analysis of renewable energy policy mixes' balance and design features in nine countries. Research Policy, 48, 103557, 2019.

DOI: $10.1016 /$ j.respol.2018.03.012. 
[18] Landry, R. \& Varone, F., The choice of policy instruments: Confronting the deductive and the interactive approaches. Designing Government: From Instruments to Governance, eds P. Eliadis, M. Hill \& M. Howlett, McGill-Queen's University Press: Montreal, pp. 106-131, 2005.

[19] Metz, F. \& Ingold, K., Policy instrument selection under uncertainty: The case of micropollution regulation. Annual Meeting of the Swiss Political Science Association, Bern, Switzerland, 30-31 Jan. 2014.

[20] Knoepfel, P. \& Bättig, C., Environmental Policy Analyses: Learning from the Past for the Future - 25 Years of Research, Springer-Verlag: Berlin, Heidelberg, 2007.

[21] Ingold, K., Fischer, M. \& Cairney, P., Drivers for policy agreement in nascent subsystems: An application of the advocacy coalition framework to fracking policy in Switzerland and the UK. Policy Studies Journal, 45, pp. 442-463, 2017.

DOI: $10.1111 / \mathrm{psj} .12173$.

[22] Lubell, M., Feiock, R.C. \& de La Cruz, E., Local institutions and the politics of urban growth. American Journal of Political Science, 53, pp. 649-665, 2009.

DOI: 10.1111/j.1540-5907.2009.00392.x.

[23] Zaugg Stern, M., Philosophiewandel im schweizerischen wasserbau: Zur vollzugspraxis des nachhaltigen hochwasserschutzes. Abteilung Humangeographie, Geographisches Institut der Universität Zürich, 2006.

[24] Jong, P. \& van den Brink, M., Between tradition and innovation: Developing flood risk management plans in The Netherlands. Journal of Flood Risk Management, 10, pp. 155-163, 2017. DOI: 10.1111/jfr3.12070.

[25] Henstra, D., The tools of climate adaptation policy: Analysing instruments and instrument selection. Climate Policy, 16, pp. 496-521, 2016. DOI: $10.1080 / 14693062.2015 .1015946$.

[26] Ingold, K., How involved are they really? A comparative network analysis of the institutional drivers of local actor inclusion. Land Use Policy, 39, pp. 376-387, 2014. DOI: 10.1016/j.landusepol.2014.01.013. 